\title{
Atlas on our shoulders
}

\author{
The Body has a Mind of its Own: How \\ Body Maps in Your Brain Help You Do \\ (Almost) Everything Better \\ by Sandra Blakeslee and Matthew \\ Blakeslee \\ Random House: 2007.240 pp. \$24.95
}

\section{Edvard I. Moser}

Like an atlas, the brain contains maps of the internal and external world, each for a distinct purpose. These maps faithfully inform the brain about the structure of its inputs. The body surface, for example, is mapped in terms of its spatial organization, with the same neural arrangement flashed through successive levels of processing - from the sensory receptors in the periphery to the thalamus and cortex in the brain. Meticulous mapping also takes into account the hat on your head and the golf club in your hand, and separate systems encode the space through which your body moves. As V. S. Ramachandran has remarked: God must be a cartographer.

In The Body has a Mind of its Own, Sandra and Matthew Blakeslee - who represent the third and fourth generations in a family of science writers - use this emerging knowledge about brain maps as a springboard for presenting some of the most exciting discoveries in neuroscience. The unifying theme is the idea that the way our body is mapped by neural circuits in the brain can account for a range of our experiences and perceptions. Using a readable and inspiring format, the authors showcase new and classic research on neural representations, without compromising accuracy.

The stories are refreshingly up-to-date, covering, for example, the emerging appreciation of the dynamic borders between maps for body and external space, and new insights

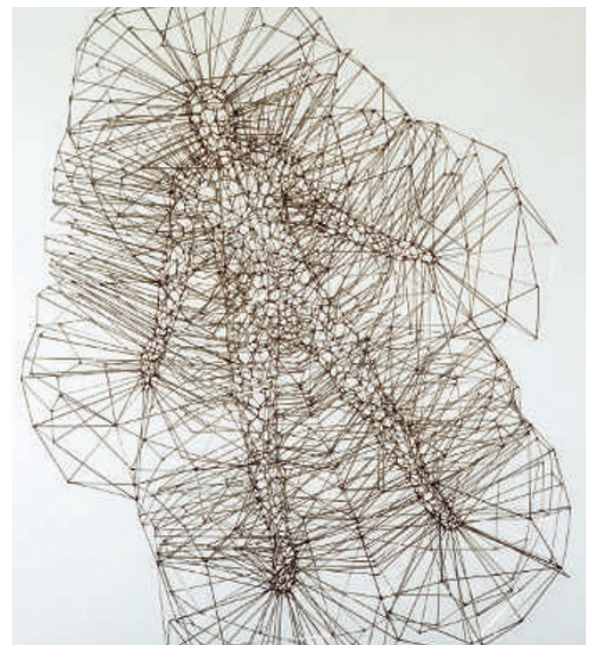

Sculptor Antony Gormley also explores how the body relates to surrounding space.

into how our own location in space is mapped by specialized cells called grid and place cells. Anecdotes and ideas from sister disciplines, including neurology, psychiatry and cultural anthropology, mix comfortably with laboratory observations. New discoveries titillate our curiosity, explaining common phenomena such as yo-yo dieting and contagious yawning as well as some more bizarre neurological abnormalities such as alien-hand syndrome and supernumerary-limb perception. Also covered are why you cannot tickle yourself, why some people have 'out-of-body' experiences, and why babies in Mali walk earlier than those anywhere else in the world.

The chapter on mirror neurons discusses their possible implications for social transmission and cultural learning. Mirror neurons fire when a monkey peels a banana, say, and when it observes another monkey peeling a banana.
They may therefore be part of the neural basis of intention, promoting learning by imitation. The authors explain how mirror neurons could participate in a wide range of primate brain functions, for example in shared perception and empathy, cultural transmission of knowledge, and language. At present we have few, if any, clues as to how mirror neurons compute or how they interact with other types of neuron, but the Blakeslees draw our attention to social neuroscience as an emerging discipline.

It is important to keep in mind that the map concept is not explanatory. We need to define what a map is to understand how perception and cognition are influenced by the spatial arrangement of neural representations. The classical maps of the sensory cortices are topographical, with neighbouring groups of neurons representing neighbouring parts of the sensory organ and thus the outside world. Other maps, such as those of the brain's spatial-representation system, are distributed with no striking correlation between firing properties and anatomical location. Both are maps in the sense that they link a feature of the external world with the activity of a neuron, but the functional implications of the map arrangements are likely to be vastly different. More complex wiring diagrams may be needed to maintain coherent localized representations in a distributed network than in a topographic system.

To the non-specialist, it may not matter whether a map is a map or not. The Body has a Mind of its Own is a thought-provoking book of wide appeal. It is a striking example of how complex issues in contemporary research can be presented to entertain everyone.

Edvard I. Moser is professor of neuroscience at the Kavli Institute for Systems Neuroscience and the Centre for the Biology of Memory, NTNU, Trondheim, Norway.

\section{Ups and downs of a senator scientist}

\section{The Volterra Chronicles: The Life and Times of an Extraordinary Mathematician 1860-1940 \\ by Judith R. Goodstein \\ American Mathematical Society/London Mathematical Society: 2007. 310 pp. \$59}

\section{Salvatore Coen}

Vito Volterra was an extraordinary mathematician. He was also a pioneer of biological modelling - a research tool that has increased in popularity by leaps and bounds since the publication of his seminal 'predator-prey' model in 1926. Volterra lived at a time when Italy was undergoing bouts of political upheaval, as a child in the wake of the
Risorgimento - the country's unification in the 1860 s - and then under Benito Mussolini's fascist regime. As a senator, Volterra withheld his support for the regime and was therefore expelled from the University of Rome in 1931 and from all Italian academies in 1934. The Volterra Chronicles is a rich biography set amid this turmoil.

Author Judith Goodstein captures the human, political and social environment of the age. The story of Volterra's life stems from his very close Italian Jewish family, with their strong patriotic sentiments. He was born in Ancona in May 1860, when the town belonged to the Church, and grew up in a country still deeply affected by the ideals of the Risorgimento. He graduated in physics from the University of Pisa and became a professor there when he was only 23 years old. Later he moved to the University of Turin, then to the University of Rome, where he married his young cousin Virginia Almagià.

The Volterra Chronicles describes the early research done by the young Volterra and his deep and precocious interest in mathematics and its applications. His papers on real and complex analysis, on mathematical physics, hydrodynamics, electrostatics, elasticity, differential, integral and integro-differential equations are still classics. In addition, he is considered a father of functional analysis, one of the main branches of contemporary 